\title{
In-situ Scanning Micro-Electrochemical Characterization of Corrosion Inhibitors on Copper
}

\author{
Bowei Zhang ${ }^{1,2}$, Junsheng $\mathrm{Wu}^{1, *}$, Dongdong Peng ${ }^{1}$, Xiaogang $\mathrm{Li}^{1}$, Yizhong Huang ${ }^{2}$ \\ ${ }^{1}$ Institute of Advanced Materials and Technology, University of Science and Technology Beijing, \\ Beijing, China \\ ${ }^{2}$ School of Materials Science and Engineering, Nanyang Technological University, Singapore \\ *E-mail: wujs@ustb.edu.cn
}

doi: $10.20964 / 110367$

Received: 14 January 2016 / Accepted: 8 March 2016 / Published: 1 April 2016

\begin{abstract}
In-situ scanning vibrating electrode technique (SVET) combined with other techniques (such as electrochemical impedance spectroscopy (EIS), atomic force microscopy (AFM) and X-ray photoelectron spectroscopy (XPS)) was used to investigate the efficiency of the mixed compound of 3amino-1, 2, 4-triazole (ATA) and sodium molybdate (SM) as a corrosion inhibitor for copper in 3.5\% $\mathrm{NaCl}$ solution in comparison with benzotriazole (BTA). The results indicate that copper shows extremely higher corrosion resistance in $3.5 \% \mathrm{NaCl}$ solution with the presence of ATA-SM inhibitor than BTA. This is due to the reaction of ATA with copper allowing the formation of a thin film incorporated with $\mathrm{MoO}_{4}{ }^{2-}$ ion precipitates on the surface of copper, which provides strong cathodic efficiency and thus is considerably protective.
\end{abstract}

Keywords: In-situ, SVET, ATA-SM, inhibitor, copper

\section{FULL TEXT}

(C) 2016 The Authors. Published by ESG (www.electrochemsci.org). This article is an open access article distributed under the terms and conditions of the Creative Commons Attribution license (http://creativecommons.org/licenses/by/4.0/). 